\title{
The Use and Value Sources of Information Used By Women During Pregnancy : Scoping Review
}

\author{
Anisya Selvia ${ }^{1}$, Dwi Ernawati ${ }^{2}$ \\ 1, Aisyiyah University, Faculty of Health Midwifery Program, \\ Jalan Ringroad Barat No.63, Mlangi Nogotirto, Yogyakarta 55592, Indonesia \\ 2, Aisyiyah University, Faculty of Health Midwifery Program, \\ Jalan Ringroad Barat No.63, Mlangi Nogotirto, Yogyakarta 55592, Indonesia
}

\begin{abstract}
:
Pregnant women, especially in the age of technologically sophistication as today have a great opportunity to find information sources about pregnancy by using various media. They can get this information through websites, blogs, online discussion forums, applications and social media platforms. Pregnant women not only use information sources to obtain information but also can share information with other users on social media.The aim of scoping review is to know the use and value sources of information used by women during pregnancy. This study employed Sciendirect and pubmed to find relevant articles, using search terms "Digital Media", "Information", "seeking" and "pregnancy". The Publication dates of those articles ranged from 2012 to 2018. 1171 was found and sorted based on inclusion and exclusion criteria, resulting in eleven articles that had been used in this study. Thematic analysis was used to identify key consepts. We grouped these key consepts into four emergent themes : use and value of Mobile Health, use and value of the Internet, health information search and the impact of social media as information search media in pregnancy.
\end{abstract}

Keywords: Digital media, Information, seeking, pregnancy

\section{Introduction}

Pregnant women, especially in the age of technologically sophistication as today have a great opportunity to find information sources about pregnancy by using various media. They can get this information through websites, blogs, online discussion forums, applications and social media platforms. Pregnant women not only use information sources to obtain information but also can share information with other users on social media (Lupton, 2016). Having a baby is a great moment that is felt by women in their lives, especially for those who have babies for the first time. This condition is a moment when they seek information actively to help them during the transition to parenthood (Grimes, 2014).

The use of the mHealth application in pregnancy is often used by pregnant women to obtain information about their pregnancy. The abundance of information sources that can be accessed by pregnant women in seeking information during

pregnancy is one of the effective strategies to provide health education during pregnancy (Connor, 2018). The existence of health information obtained by pregnant women to be able to carry out regular Antenatal Care check-up can potentially reduce maternal and infant morbidity (Lund, 2014). Information seeking is also done by pregnant women to discover what things should not be consumed during pregnancy (Jarlenski, 2016).

Pregnant women can also use social media as a source of information seeking and sharing information in pregnancy with other users (McCarthy, 2017). Pregnant women use the internet especially social media to get information and support during the transition to parenthood (Harpel $\mathrm{T}$, 2018). The survey results showed that three quarters of pregnant and childbirth women said that they received information about pregnancy and birth from the internet (Gao, 2013).

Considering how many information sources are used by pregnant women in the modern era recently to obtain information about their pregnancies, Scoping Review explores how the use and benefits of information sources as a medium for information seeking in pregnancy through websites, blogs, online discussion forums, applications and social media platforms and things needed by pregnant women as an effort to reduce the Maternal Mortality Rate (MMR) and Infant Mortality Rate (IMR). 


\section{DATA SOURCES}

The Scoping Review uses grouping review methodology as suggested by Arksey and O'Malley and further developed by Levac. There are four reasons for conducting Scoping Review: (1) to examine the range and nature of research activities, (2) to determine the value of conducting a full systematic review, (3) to summarize and disseminate research findings, and (4) to identify research gaps in the existing literature.

The stages carried out in this scoping review consist of: (1) identifying research questions, (2) identifying relevant studies, (3) selecting studies, (4) mapping data, and (5) compiling, summarizing and reporting results.

\section{Step 1: Identify research questions}

This review specifically aims to find out: How to use and benefit information sources as a medium for information seeking in pregnancy.

\section{Step 2: Identify relevant studies}

This study uses a ScienceDirect and Pubmed database to identify relevant article studies. To find relevant articles, the keywords used are "Digital Media", "Information", "seeking" and "pregnancy". The date of publication of the article ranges from 2012 to 2018.

The focus of the research in this scoping review is pregnant women who use a variety of information sources in pregnancy; websites, blogs, online discussion forums, applications and social media platforms. The use of the internet is indeed a necessity that is currently very popular with the public, especially pregnant women, so every article related to the internet media, social media, and mobile health is included. There are no restrictions imposed on the date of publication to ensure that the review is comprehensive. Reviews are included in international literature and are limited to publications in English. Studies investigating information found by pregnant women during pregnancy that are not related to sources of information in pregnancy were included in this review.

\section{Step 3: Selection of Study}

In the search for articles identified 1171 articles, after filtering for relevance obtained 30 articles. Then, a further article filtering was conducted to find the right and complete reference regarding the use and benefits of information sources as a media for information seeking in pregnancy and found 11 articles to be used for Scoping Review. The author screens the titles and abstracts of all articles to be used as inclusion criteria. Full text studies are taken and reviewed independently based on these criteria. Hence, it is left 11 articles for final review.

\section{Step 4: Mapping Data}

Data from 11 articles were extracted to include key criteria such as research location, research population, research objectives, methodology, and significant findings or recommendations. The author independently recorded information and then compared the extracted data. The author consulted with the counselor until all the content was analyzed and became a theme.

\section{Step 5: Arrange, Summarize, and Report the results}

As what has been conducted by Levac et al. The author takes a three-phase approach to compile, summarize, and report results. First, descriptive numerical analysis is provided which includes the number of articles, year of publication, and type of study.

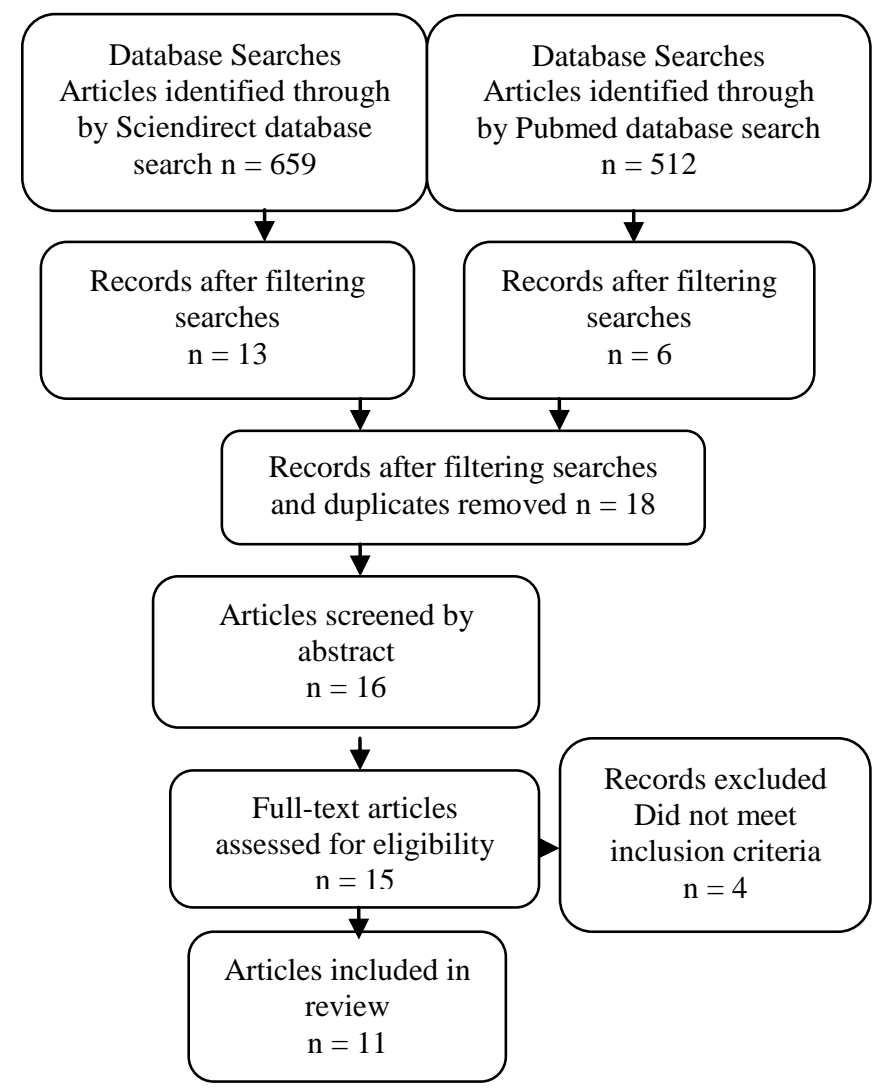

Figure 1. Flowchart of the literature search process

\section{FINDINGS}

\section{Descriptive summary and thematic analysis}

This review consists of articles published between the year of 2012 to 2018 , authors in the literature sources taken from American countries $(n=3)$, Australia $(\mathrm{n}=2)$, China $(\mathrm{n}=1)$, Zanzibar $(\mathrm{n}=1)$, United Kingdom $(n=1)$, Pittsburgh $(n=1)$, Atlanta 
$(n=1)$, Sweden $(n=1) .9$ articles taken in this literature are articles with quality (Q1), 1 article with quality (Q2) and 1 article with quality (Q3). 4 articles are qualitative studies, 3 articles are crosssectional studies, 3 articles are web-surveys, and 1 article is a Randomized Control Trial.

Nine Q1 Projects were carried out in several countries including China, United Kingdom, Zanzibar, Pittsburgh, Atlantic, Australia and Sweden. One Q2 project was carried out in an American country and one Q3 project was also conducted in America. Three journals discuss the use of Mobile Health. Two journals discuss internet use in pregnancy, two journals discuss the search for health information in pregnancy and four journals discuss the impact of social media in pregnancy.

\section{Theme from data}

Data extracted from this scoping review article is organized into several themes. The themes included in this literature review consist of: Use of Mobile Health, internet use, search for health information and the impact of social media in pregnancy to improve maternal and child health.

\section{Use of Mobile Health as a media for information seeking in pregnancy}

The articles were selected and taken from several that are part of the use of Mobile Health as a media for information seeking in pregnancy. Given the high use of cell phones throughout the world today, cellular-based interventions are admitted as a potentially powerful tool to be able to disseminate health information. Cellular-based health information (mHealth) appears as a useful tool for increasing access to health care, especially in developing countries, especially related to antenatal care (Connor K, 2018).

The main purpose explained by all the papers in this scoping review is to determine the extent to which prenatal cellular health applications (mHealth applications) can be used and desired for women seeking information about labor.

The results obtained from several articles relating to the use of Mobile Health as a media for information seeking in pregnancy health in pregnancy state that the application of mHealth can be a health education tool that is useful in providing information about health during pregnancy, childbirth and childbed and newborn care easily accessed by the mother (Connor $\mathrm{K}, 2018$ ). Another article mentions that information about pregnancy obtained by mothers through various sources of information can increase maternal pregnancy visits to health workers who are recommended and there is a tendency to improve the quality of care during pregnancy (Lund S, 2014). This is reinforced by another article stating that pregnant women are accustomed to finding information about pregnancy through various kinds of information sources offered by digital technology (Lupton D, 2016).

\section{Use of the Internet as a medium for information seeking in pregnancy}

In this article, the majority of the papers included discuss how pregnant women use the internet to find information regarding pregnancy (Gao, L, 2013) and the use of the internet as a source of information during pregnancy (Bjelke M, 2016). Finding in the article stated that internet is information source used by the Chinese community to find information about her pregnancy. Hence, professional health workers must be able to guide pregnant women to more carefully filter the information they obtain. Thus, usually health workers in China always discuss information obtained by their patients on the internet while they are visiting. Therefore, it is recommended that professional health workers such as midwives should provide education about pregnancy issues and ask pregnant women about information that is not clear enough to avoid misinterpretation when obtaining information on the internet (Gao, L, 2013).

Almost all the women in this article use the internet to find information about their pregnancies even though they are satisfied with the information they get when they do an Antenatal Care check-up. Using the internet is seen as a complement to information from health workers (Bjelke M, 2016).

\section{Search for health information for pregnant women}

Searching for information about health is very popular with pregnant women, especially for women who are newly pregnant. The results obtained from several articles relating to the search for health information for pregnant women state that pregnant women who consume drugs also urgently need information-seeking media to obtain information about the health of their babies in the womb when they consume these drugs. That is why the internet is very necessary for pregnant women today (Jarlenski M, 2016). In addition, conducting discussions with health workers, especially midwives, is also an important source of information for pregnant women because many pregnant women re-verify information obtained on the internet (Grimes H, 2014). 
Impact of Social Media as a media for information seeking in pregnancy

The use of social media is increasing rapidly, various age groups and social media backgrounds use social media to seek for information, as well as the pregnant women. This article discusses pregnant women who use social media platforms to access information from midwives about information on their pregnancies. The results of the study state that information and ongoing needs are needed by women owned by midwives (McCarthy R, 2017). One of the social media used by women is Facebook. In this article, we discuss women who use Facebook as a social media for supportive and information purposes. This study provides great benefits for health workers, because by using Facebook, health care can provide interventions, information and support for pregnant women through developing social media in the community (Harpel T, 2018). Social media does play a role recently that health care providers must strive to provide innovation regarding the promotion of health services, especially those related to maternal and child health (Baker B, 2018). Social media can provide various benefits because it has content that is not only related to women, maternity but also contains content on contraception and infant care (Lewkowitz A, 2015).

\section{CONCLUSION}

This Scoping Review identified 11 relevant publications taken from sources in the last 7 years involving information on Mobile Health use, internet usage, searching for health information on pregnancy and the impact of social media in pregnancy. The findings indicate that (mHealth) appears as a useful tool for increasing access to health care, especially in developing countries, precisely related to antenatal care (Connor K, 2018). This is reinforced by another article stating that pregnant women are accustomed to finding information about pregnancy through various kinds of information sources offered by digital technology (Lupton D, 2016).

The internet is a source of information media used by Chinese people to find information about their pregnancies. Almost all pregnant women use the internet to find information related to their pregnancies even though they are satisfied with the information they get when they do an Antenatal Care check-up. Using the internet is seen as a complement to information from health workers (Bjelke M, 2016). Discussing with health workers especially midwives is also an important source of information for pregnant women because many pregnant women re-verify information obtained on the internet (Grimes H, 2014). Social media can also provide various benefits because it has content that is not only related to pregnant women, maternity and childbirth but also contains content on contraception and infant care (Lewkowitz A, 2015).

\section{DECLARATION OF CONFLICTING INTERESTS}

This article is the author's original work, is not under consideration for publication elsewhere, and has not received prior publication. This article was originally made when the author doing Master courses, funded by author

\section{ACKNOWLEDGMENT}

The author would like to thank to my supervisor Mrs. Dwi Ernawati from the Universitas 'Aisyiyah Yogyakarta for her insights, comments, and expertise that greatly improved the manuscript.

\section{References}

[1] Arksey H, O'Malley L. Scoping studies: towards a methodological framework. Int $\mathbf{J}$ Soc Res Methodol 2005;8(1):19-32.

[2] Baker, B., \& Yang, I. (2018). Social media as social support in pregnancy and the postpartum. Sexual \& Reproductive Healthcare, 17, 31-34.doi:10.1016/j.srhc.2018.05.003

[3] Bjelke, M., Martinsson, A.-K., Lendahls, L., \& Oscarsson, M. (2016). Using the Internet as a source of information during pregnancy $-A$ descriptive cross-sectional study in Sweden. Midwifery,40,187191.doi:10.1016/j.midw.2016. 06.020

[4] Connor, K., Wambach, K., \& Baird, M. (2018). Descriptive, Qualitative Study of Women Who Use Mobile Health Applications to Obtain Perinatal Health Information. Journal of Obstetric, Gynecologic \& Neonatal Nursing.doi:10.1016/j.jogn.2018.04.138

[5] Gao, L., Larsson, M., Luo, S., 2013. Internet use by Chinese women seeking pregnancyrelated information. Midwifery 29, 730-735. https://doi.org/10.1016/j.midw.2012.07.003

[6] Grimes, H. A., Forster, D. A., \& Newton, M. S. (2014). Sources of information used by women during pregnancy to meet their information needs. Midwifery, 30(1), e26e33.doi:10.1016/j.midw.2013.10.007

[7] Harpel T. Pregnant Women Sharing PregnancyRelated Information on Facebook: Web-Based Survey Study J Med Internet Res 2018;20(3):e115 DOI: 10.2196/jmir.7753 
[8] Jarlenski, M., Tarr, J. A., Holland, C. L., Farrell, D., \& Chang, J. C. (2016). Pregnant Women's Access to Information About Perinatal Marijuana Use: A Qualitative Study. Women's HealthIssues, 26(4),452459. doi:10.1016/j.whi.2 016.03.010

[9] Levac D, Colquhoun H, O'Brien K. Scoping studies:advancing the methodology.Implement Sci 20105(69).

[10] Lewkowitz, A. K., O’Donnell, B. E., Nakagawa, S., Vargas, J. E., \& Zlatnik, M. G. (2015). Social media messaging in pregnancy: comparing content of Text4baby to content of free smart phone applications of pregnancy. The Journal of Maternal-Fetal \& Neonatal Medicine,29(5),745751.doi:10.3109/14767058. 2015.1017460

[11]Lund, S., Nielsen, B.B., Hemed, M., Boas, I.M., Said, A., Said, K., Makungu, M.H., Rasch, V., 2014. Mobile phones improve antenatal care attendance in Zanzibar: a cluster randomized controlled trial. BMC Pregnancy Childbirth 14, 29. https://doi.org/10.1186/1471-2393-14-29

[12] Lupton, D. (2016). The use and value of digital media for information about pregnancy and early motherhood: a focus group study. BMC
Pregnancy

and

16(1). doi:10.1186/s12884-016-0971-3

[13] McCarthy, R., Choucri, L., Ormandy, P., \& Brettle, A. (2017). Midwifery continuity: The use of social media. Midwifery, 52, 3441.doi:10.1016/j.midw.2017.05.012

\section{Author Profile}

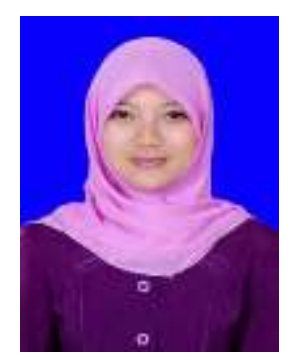

Anisya Selvia is a final year midwifery master student who is completing her final assignment at Aisyiyah University of Yogyakarta. She studied at Faculty of Health Midwifery Program. This article is her second project. Her first article concern about technology for pregnant woman. 